\title{
US drug strategy runs counter to Canada's
}

A new US drug-control strategy to increase treatment and reduce incarcerations is strikingly at odds with the Harper government's drive to imprison more Canadians for drug offenses, Canadian drugpolicy analysts say.

"The Obama administration is really trying to scale up addiction treatment while the Canadian government retreats from it," notes Thomas Kerr, codirector of the Addiction and Urban Health Research Initiative at the British Columbia Centre for Excellence in HIV/AIDS in Vancouver. "The US efforts are supportive of harm reduction, while Canada has abandoned it. It's great to see some of the things the Americans are doing: we can only hope [Prime Minister] Stephen Harper will take notice."

Under US President Barack Obama's 2013 Drug Control Strategy, released in late April, the White House claims to have "rebalanced national drug control policy to reflect the complexity of drug use as both a public health and public safety issue" (www.white house.gov/ondcp/2013-national-drug -control-strategy).

The aim, explained Gil Kerlikowske, director of the Office of National Drug Control Policy and Obama's top drugpolicy advisor, is to chart a third way between drug-legalization advocates seeking "silver bullet" solutions to drug control and "a law enforcement-only 'War on Drugs' mentality."

The new strategy dedicates more than US\$10.5 billion to prevention and treatment, compared to US\$9.6 billion for domestic law enforcement. The White House aims to create more drug courts and direct many of those arrested to treatment facilities. "We cannot arrest our way out of the drug problem," the strategy warns, while stressing that "decades of scientific study show that addiction is a disease of the brain that can be prevented and treated."

The overall approach offers a blunt counterpoint to Canada's National

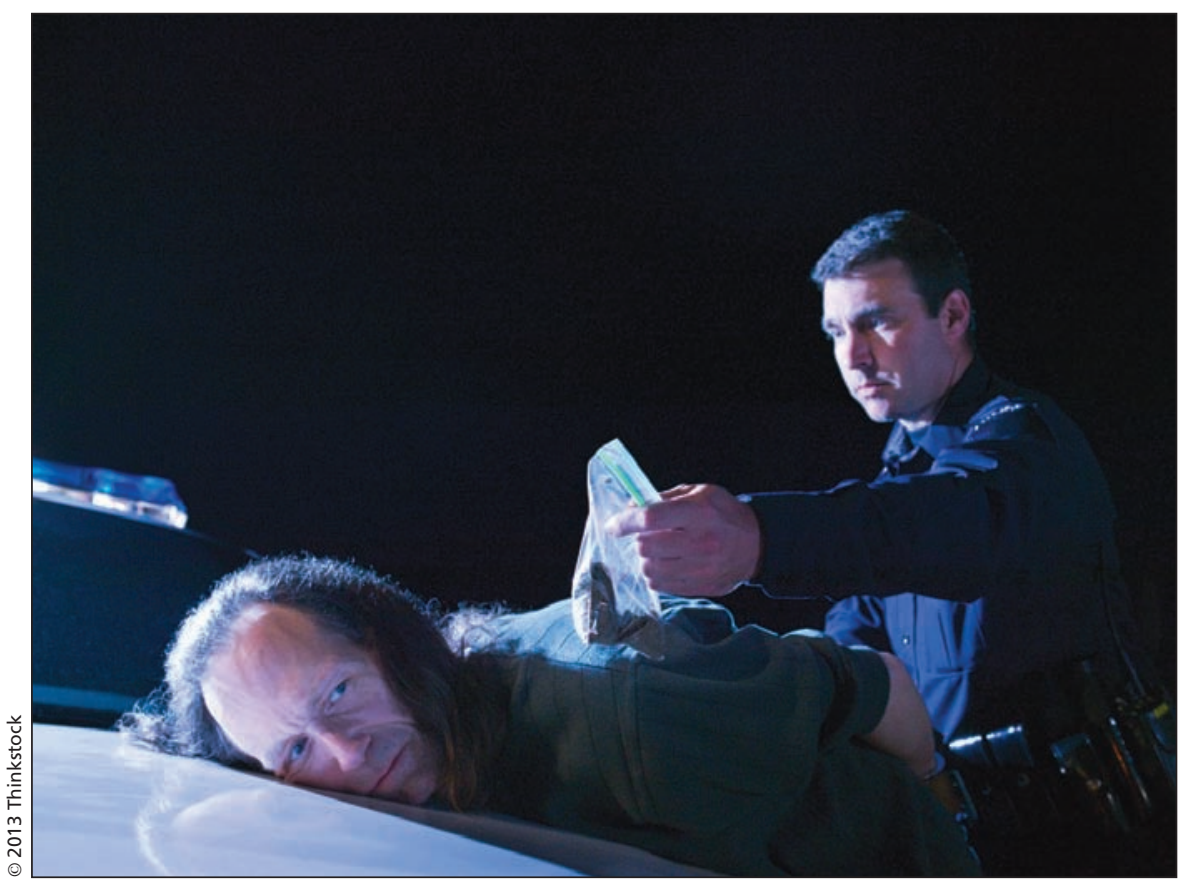

The United States has resolved to find a better solution to drug control than "a law enforcement-only 'War on Drugs' mentality."

Anti-Drug Strategy, launched in 2007, says Connie Carter, senior policy analyst with the Canadian Drug Policy Coalition and the Centre for Applied Research in Mental Health and Addiction at Simon Fraser University in Vancouver.

Carter notes that Canadian drug policies are in large part unexplained by the government, which has removed detailed information explaining the National Anti-Drug Strategy — which has had a budget of more than $\$ 500$ million since 2007 — from its website in recent months (www.nationalanti drugstrategy.gc.ca/).

"There is almost nothing available to the public now about the details of our drug strategy whereas with Obama's new plan we are able to read it in detail and see what they are up to."

Carole Saindon, spokeswoman for the federal Department of Justice, confirmed that detailed information about the antidrug strategy is no longer available from the government, but refused to elaborate.
In resetting US drug policies, the strategy notes that the nature of the problem has shifted. While cocaine was the major preoccupation for decades, production in Colombia has dropped dramatically and usage in the US has decreased $50 \%$ since 2006. Meanwhile, prescription drug misuse is soaring. In 2009, according to the White House, 5.3 million Americans age 12 and older used pain relievers nonmedically, and treatment admissions linked to prescription opioids rose $535 \%$ between 1999 and 2009.

In spotlighting prescription drug misuse as the nation's most critical drug-abuse problem, the US strategy explains that pain relievers are linked to nearly twice as many overdose deaths as cocaine and more than five times as many as heroin. Noting that more Americans die from drug overdoses than car crashes or gunshot wounds, the strategy warns that "prescription drug overdoses are placing enormous burdens upon communities across the country. So pronounced are 
these consequences that the US Centers for Disease Control and Prevention has characterized prescription drug overdose as a public health epidemic."

To help soften the overdose crisis, in December, the US government granted physicians discretion to dispense buprenorphine in opioidtreatment programs, overturning earlier strictures that restricted physician discretion. The Obama administration is also increasing research funds to develop new addiction medications.

Along with the new attention to reducing incarcerations, expanding treatment and preventing overdoses, the White House wants to end health-insurance barriers against people with preexisting conditions, including people with mental health and substance-use disorders. And in an explicit effort to expand harm-reduction programs of the exact type the Harper government opposes, the Obama administration has pushed hard to expand needle-exchange programs. In 2012, Congress reinstated the ban on most federal funding for syringe services programs.
Ethan Nadlemann, executive director of the Drug Policy Alliance, a New York-based group promoting drug law reforms, says the new US strategy is a strong endorsement of the concept of harm reduction disavowed by Canada's strategy. "There has been a remarkable shift in rhetoric away from the idea of a drug free society," Nadlemann adds. "They need to be complimented for their evolution." - Paul Christopher Webster, Toronto, Ont.

CMAJ 2013. DOI:10.1503/cmaj.109-4507 